\title{
LA DESCRIPCIÓN DE ESPACIOS URBANOS Y SUS CONVENCIONES. DEL ROMANTICISMO A LA NOVELA INTELECTUAL
}

\author{
Isabel ROMÁN ROMÁN
}

Universidad de Extremadura

\section{RESUMEN}

Proponemos un recorrido por diversas novelas españolas de la segunda mitad del siglo XIX y primeras décadas del s. XX, para entender cómo evoluciona la descripción urbana en ellas. Nos interesan particularmente dos aspectos: el conocimiento de la ciudad como una expedición en la que el narrador actúa como guía de sus lectores, y el convenio de la vista panorámica totalizadora para describir escenarios en las aperturas de las novelas realistas.

Palabras clave: descripción de espacios, novela española S. XIX, costumbrismo, naturalismo, narrativa de vanguardia.

\section{ABSTRACT}

In order to understand the evolution of urban description from the 2nd half of the 19 th Century to the early years of the 20th Century, we propose a journey through a number of Spanish novels from this same period.

We pay particular attention to two important aspects: the first is the presentation of the cities as an expedition, where the narrator acts as a guide for the reader. The second deals with the use of the all-enhancing Panoramic view convention to describe scenes in the openings of realistic novels.

Key words: description of settings, Spanish XIX century novels, Costumbrismo, Naturalismo, Avant-garde narrative. 
Proponemos un recorrido en el que confiamos a la selección oportuna de algunas muestras narrativas y a su comentario, el reconocimiento de cómo evolucionan algunas convenciones de la descripción urbana desde el Romanticismo hasta las novelas intelectuales de Ramón Pérez de Ayala y los experimentos narrativos de Ramón Gómez de la Serna.

La conclusión de este trayecto pretende iluminar mediante estos dos autores el cambio en ciertos tópicos descriptivos de espacios urbanos, especialmente en el que plantea el conocimiento de la ciudad como una expedición en la que el narrador actúa como guía de sus lectores, y el convenio de la vista panorámica totalizadora para describir escenarios en las aperturas de las novelas realistas.

\section{DE LA CIUDAD DEL COSTUMBRISMO A LA CIUDAD DE LA NOVELA NATURALISTA}

El convenio costumbrista permitía la tipificación del paisaje y de los pueblos, y si para el novelista bastaba con dar un aire de familia o color local a un escenario, el ámbito descriptivo no tenía la misión de aportar gran cosa a la singularización de los personajes.

Si intentásemos sumar todo lo que las novelas de Valera nos permiten conocer sobre la ficticia ciudad de Villabermeja, tal vez nos sorprendería lo escueto del resultado. Partiendo de 1874 y Pepita Jiménez, comprobamos la escasez de detalles sobre el escenario del pueblo en el que transcurre la novela, junto a otras omisiones y reticencias que pretenden reforzar la verosimilitud. El ocultar datos que pudieran identificar a los protagonistas en su lugar implica precisamente la existencia real y contemporánea de personajes, lugares, hechos.

En Pepita Jiménez, las descripciones de interiores y de paisajes a cargo del joven Luis, con su tío como receptor y corresponsal, buscan la verosimilitud en el contexto. Su emoción ante el estallido de la primavera, asociada al amor incipiente, justifica las poéticas y amplias descripciones de los campos que realiza el protagonista en sus distintas salidas en marzo y abril. Así mismo, la casa de Pepita aparece descrita por él en dos ocasiones con motivo de reuniones y tertulias. Sin embargo, sus descripciones del paisaje serían aplicables a infinidad de lugares, y las de la casa presentan también una perspectiva generalizadora que vendría a incluirla en la tipología de las casas lugareñas andaluzas de ricos.

La Introducción en 1875 de Las ilusiones del doctor Faustino, insólitamente titulada, anuncia «Donde se trata de Villabermeja, de D. Juan Fresco y de las ilusiones en general». Pero en verdad el espacio de Villabermeja se liquida 
en unas líneas; y más tarde, la descripción espacial del capítulo I es tan escasa que de Villabermeja se menciona sólo su castillo, trasladándose el interés descriptivo algo más demorado a la casa solariega de la dinastía de los Mendoza a la que pertenece el protagonista. En El comendador Mendoza, de 1876, el inicio del capítulo II sitúa una parte de la historia en «la pequeña ciudad, que dista dos leguas de Villabermeja, cuyo nombre no he querido nunca decir, y donde he puesto la escena de mi Pepita Jiménez» ${ }^{1}$. Y como si hubiese creado un preciso escenario inolvidable, Valera advierte al lector: «Para la mejor inteligencia de todo, y a fin de evitar perífrasis, pido al lector que siempre que en adelante hable yo de la ciudad entienda que hablo de la pequeña ciudad ya mencionada».

De nuevo dos años más tarde, Doña Luz se abre con la breve mención de la ya recurrente Villabermeja, presuponiendo a estas alturas que es muy conocido esta especie de archilugar andaluz, que algunos críticos no dudan en asociar a la propia vida de Valera, en las mixturas de ficción y autobiografía que el propio novelista gusta de sembrar en los prólogos de sus obras, donde advierte que los lugares de la acción están muy cerca o de su lugar natal o de otros en los que heredó propiedades de su padre.

De una manera algo mecánica, Juan Valera parece confiar en que la mixtura autobiográfica, la recurrencia de topónimos y el recuerdo de vagos escenarios anteriores será suficiente para que el lector reconstruya un mundo geográfico y de costumbres autónomo en un conjunto de sus novelas. Busca la complicidad con el lector asiduo sin haber creado un espacio con la suficiente autonomía y fuerza como para ser recordado por sí mismo y en su interacción con los personajes que lo habitan. También es cierto que el lector no requiere particular memoria para evocar el espacio prototípico de muchos pueblos andaluces con sus casonas y plazas, su iglesia y el influjo de ésta en el calendario eclesiástico-festivo de la localidad, sus fuerzas vivas, sus costumbres, sus circunstancias electorales y la manipulación caciquil, etc., etc.

Por otra parte, es comprobable cómo en la narrativa costumbrista el espacio urbano aparece en relación de oposición a la naturaleza y a los espacios rurales esquematizados e idealizados, en un modelo semejante al «menosprecio

1. En adelante, y siguiendo una propuesta que escuché muchas veces al querido profesor John H. Kronik, en los casos de obras cuyo texto ya fijado se haya difundido ampliamente en gran número de ediciones modernas disponibles, preciso todo lo posible la información que permita localizar con facilidad los textos referidos, sea cual sea la edición manejada por el lector. En los casos en los que no existan ediciones modernas, o sean escasas y raras las disponibles, se explicita la edición y paginación exactas a las que corresponden los textos citados. 
de corte y alabanza de aldea». Recordemos casos como La gaviota de Fernán Caballero, o la novela de costumbrismo regional extremeño Corte y cortijo de 1870, en la que Antonio Hurtado da voz mediante el modelo epistolar a las dos corresponsales que desarrollan la polarización del título: la corte madrileña en la que una habita aparece como el lugar de la hipocresía social, de la soledad más absoluta en medio del fingimiento y las apariencias engañosas, frente a la aldea -aquí el campo extremeño de un rico propietario, ubicado con referencias escasas e imprecisas- como promesa de la liberación personal. (Hurtado, 2010: 26-29).

Parece claro en la mayoría de los casos que las «polaridades espaciales» pueden ir más allá de la construcción de ambientes necesaria en una novela; en efecto, suelen orientarse a reforzar el sentido de la trama para que el lector realice una lectura simbólica de la confrontación de espacios. (Zubiaurre, 2000: 62-63).

Pero progresivamente, la ciudad irá apareciendo de modo autónomo, sin servir tan directamente a una tesis que la enfrente a ningún otro espacio, aunque los escenarios rurales sigan formando parte de decenas de novelas en contextos de viajes y vacaciones de los personajes urbanos, entre otros. Y a la inversa, la ciudad puede ser el lugar de desplazamiento de personajes rurales que viajan para resolver sus asuntos, realizar visitas varias, por motivos de estudios... lo que permite a veces el contraste entre el lugar de origen y el movimiento de la urbe a la que el personaje debe adaptarse. La Doña Berta de Clarín (1892) en el capítulo VIII del relato se desplaza a Madrid desde el pueblecito asturiano cuya detallada ubicación abre el texto. La capital, donde transcurre el relato hasta el capítulo XI y último, aparece sólo como un tráfago de calles que la dama ni siquiera observa. No hay descripciones como tales, debido al ensimismamiento y la finalidad obsesiva con la que la anciana recorre el centro de Madrid. Pese a la escasez de juicios de valor sobre la corte en Doña Berta, un fino crítico como Kronik creyó ver en esta novela, en fecha tan tardía como el fin de siglo, la pervivencia de una de «las grandes preocupaciones de los escritores realistas: las tensiones entre tradición y progreso, entre el idilio del campo y las amenazas de la ciudad». (Kronik, 1999: 99).

Sin duda es asunto no menor y que desborda cualquier cronología, ya que el menosprecio de corte y alabanza de aldea forma parte de la tesis de algunas novelas regionalistas y, transformado, de las novelas que asumen desde fines del siglo XIX las ideas regeneracionistas.

Si pensamos en el conocido ejemplo de Peñas arriba, son bien explícitos los juicios de valor del narrador autobiográfico que, en su breve regreso a Madrid (la capital ocupa escasas líneas en la apertura, y una breve parte 
del penúltimo capítulo) reconoce que su vida ha de seguir en Tablanca y la Montaña cántabra que tan placenteramente ha recorrido en sus continuas «andadas por montes y barrancas», y en consecuencia, ha descrito a lo largo de toda la novela.

Algunos tiempos y espacios, y las escenas prototípicas que transcurren en ellos -patios y cruces de mayo; praderas y romerías en honor de santos; fincas campestres y fiestas de inicio de la primavera; salones burgueses y tertuliasque ya venían presentados desde los artículos de costumbres románticos, permanecerán tanto en las novelas costumbristas como en el naturalismo más maduro, con interesantes transformaciones que merecen el análisis.

Lugares urbanos como plazas, paseos, teatros, casinos, serán el escenario preferido del ritmo burgués de la vida social. Los encuentros $-\mathrm{y}$ los espacios y situaciones narrativas- que propician las fiestas de carácter religioso (Día de los Difuntos, Carnaval, Semana Santa...) perviven en algunas novelas urbanas, sobre todo en las ambientadas en ciudades provincianas. Como en las novelas costumbristas, tanto la iglesia del pueblo como la catedral en la ciudad siguen marcando una parte esencial de la vida comunitaria. Tanto, que no es raro que la temporalidad de ciertas novelas del realismo español se organice según el calendario religioso, con el ejemplo señero de La Regenta, ya estudiado modélicamente. (Alarcos, 1952: 141-160).

El gran cambio se opera cuando la descripción no se pone al servicio de una tesis, sino que se vincula sobre todo al personaje, lo que se produce sobre todo en el realismo naturalista. Mientras más se asocien los espacios a los procesos interiores de los personajes, más se van alejando de la pura descripción funcional o de la «recreación colorista» propia del costumbrismo. (P. Landy, 1979: 15-18).

Ya a fines del s. XVIII, e intensamente en el Romanticismo, el paisaje aparecía vinculado a la psicología y los sentimientos del personaje, de tal modo que en el Romanticismo era usual el paralelismo entre paisaje y subjetividad de quien lo contempla. De ello, aún a las alturas de 1852, encontramos una interesante muestra con reflexión teórica superpuesta, en el final del capítulo XI de la Parte I de la Clemencia de Fernán Caballero. Aparece primero el paisaje, inspirador e idealizado tal como lo ve Clemencia, y luego las reflexiones sobre el poder de evocación espiritual y hasta religiosa que el entorno marino suscita en la protagonista: «Todo aquello le infundía mil sensaciones y pensamientos, pues como dice Balzac: le paysage a des idées; el paisaje tiene ideas».

El Naturalismo estrecha los vínculos entre naturaleza, medio ambiente y seres humanos, por lo que no es conveniente generalizar, como hace Zubiaurre, a toda la novela realista del siglo XIX el fuerte contenido semántico con 
el que aparece el espacio en el naturalismo. El espacio «habla indirectamente de los personajes y contribuye metonímicamente a su definición», sí, pero habría que precisar en qué autores y épocas de su producción. (Zubiaurre, 2000: 22). Con La Regenta como objeto de estudio, Bobes expuso observaciones muy agudas, poniendo de relieve cómo los espacios se hacen símbolo de los personajes, ya sea por identificación o por contraste, además de entablarse oposiciones significativas con otros espacios presentes en el texto. (Bobes Naves, 1985: 213).

Se hace necesario distinguir las peculiaridades del realismo naturalista aplicado al mundo rural (en novelas regionales como La madre Naturaleza) de las que resultan de aplicarlo a un ámbito urbano. Pero en ambos casos la descripción de espacios (sean éstos paisajes naturales o sean calles y barrios urbanos) estará en conexión con la peripecia vital de los personajes, con su caracterización, con sus eventuales estados de ánimo y percepciones momentáneas. Y como bien sabemos, para el realismo naturalista el espacio será una componente del medio que determina al personaje o que al menos le influye conjuntamente con otros factores. Por ello la densidad y rasgos de los pasajes descriptivos en una novela se relaciona íntimamente con la caracterización de los personajes protagonistas y viceversa, asunto al que dedicaremos un epígrafe de este recorrido.

Zola explicó sus ideas sobre la función de las descripciones detalladas en las novelas naturalistas, a la par que se defendió a sí mismo del rechazo que habían recibido las cinco magnas descripciones de Paris que cerraban sendas partes de la novela Une page d'amour. El gran teórico y novelista del naturalismo avisó de que la descripción ya no podía ser ornamental, sino que tendría que estar vinculada con el ser humano, imbricada con él, y no constituir párrafos cerrados en sí mismos y ajenos a la peripecia humana. Es la única forma, avisa, de que la descripción alcance interés humano y novelesco. (Zola, 1989: 202).

Ciertas propuestas de Zola tienen su antecedente en Balzac, para quien el espacio era también un aspecto narratológico fundamental, si bien más orientado a la evocación de ambientes. Cuando Balzac explicaba en 1842 en el famoso prólogo de La Comedia Humana el sentido de agrupar sus novelas en seis ciclos dentro del conjunto, aclaraba que mediante las «Escenas de la vida privada», las de la vida de provincias y las correspondientes a la vida de París, buscaba dar una idea de las variedades de Francia, entendiendo que cada parte tenía su propio color local. La descripción detallada de espacios es uno de los factores que le servirán para dar una idea de las diferentes regiones del país, según declara: «Mi obra tiene su geografía, como tiene su genealogía 
o sus familias, sus lugares, sus cosas, sus personajes y sus hechos.» (Balzac, 1987: 22)

Con otro punto de vista, declaraba Zola por su parte que el hombre no puede separarse de su medio, puesto que «su vestido, su casa, su pueblo, su provincia le completan». Ya que el personaje es el centro, las «eternas descripciones» que algunos detractores le reprochaban tenían la misión de explicar el medio en el que la persona se desenvuelve, imprescindible para entender el mundo intelectual y emotivo del personaje. (Zola, 1989: 199-204).

Aunque la Marineda de Pardo Bazán es tan ficticia como la Villabermeja de Valera, difieren los modos de crear estas ciudades, que recurren en sendos ciclos narrativos. Pese a todo, las trazas costumbristas de esta última son reconocibles, como lo son en los entornos geográficos de los grandes novelistas del siglo. (Ayala y Rubio, 1985: 68). Reconoce Pardo Bazán, en el Prólogo de La Tribuna, 1882, que Marineda es de la misma estirpe que ciertas ciudades ficticias de las novelas románticas, y que pertenece al conjunto de espacios de la geografía moral de España a la que se refirieron Galdós y Pereda:

Quien desee conocer el plano de Marineda, búsquelo en el atlas de mapas y planos privados, donde se colecciona, no sólo el de Orbajosa, Villabermeja y Coteruco, sino el de las ciudades de $\mathrm{R}^{* * *}$, de $\mathrm{L}^{* * *}$ y de $\mathrm{X}^{* * *}$, que abundan en las novelas románticas. Este privilegio concedido al novelista de crearse un mundo suyo propio, permite más libre inventiva y no se opone a que los elementos todos del microcosmos estén tomados, como es debido, de la realidad. Tal fue el procedimiento que empleé en La Tribuna, y lo considero suficiente -si el ingenio me ayudase- para alcanzar la verosimilitud artística, el vigor analítico que infunde vida a una obra.

Aunque tras aportar al lector las típicas coordenadas de tiempo y espacio aclare que la novela, pese a su marco histórico reciente, es «en el fondo un estudio de costumbres locales», nada más lejos de la creación costumbrista del escenario de una ciudad. Los detalles espaciales sobre Marineda, en los primeros capítulos de la novela, escasos y funcionales, están estrictamente vinculados con las actividades que se van a suceder en ellos: la salida de misa y el paseo en el capítulo III justifican la descripción de «las Filas», estrecho paseo con raquítica vegetación, antecedente del parque inglés que con toda verosimilitud la autora atribuye a la Marineda contemporánea a la escritura de la novela. Sin embargo, la descripción del paseo se justifica desde la mirada de Amparo, como es habitual en el realismo maduro, que asocia la descripción de ambientes al punto de vista e intereses de un personaje, según recordaremos más adelante: «miraba Amparo con gran interés el espectáculo que el paseo presentaba». 
En el capítulo XVII aparecen breves brochazos descriptivos acerca de los arrabales del pueblo, pero no los redondos párrafos casi exentos acerca del escenario que a menudo encabezan capítulos o dan inicio a aquellas novelas en las que el narrador se sitúa como todopoderoso guía de sus lectores.

Algo más detallada, y de poderoso valor en sus analogías metafóricas, es la descripción de la fábrica en el capítulo XXI, «Tabaco picado». Pero sorprendentemente, el más importante enclave enteramente descriptivo no aparece ¡hasta el capítulo XXX! explícitamente titulado «Dónde vivía la protagonista», lo que según la tradición descriptiva podría haberse situado muy al comienzo de la novela. El lector encuentra ahí una extraordinaria descripción del barrio obrero, con sus viviendas, con sus pequeños comercios «que, acatando la ley que obliga a los organismos a adaptarse al medio ambiente, se acomodaban a la pobreza de las barriadas», su paisanaje... y la vivienda concreta de la protagonista. Por lo demás, las notas sobre toponimia urbana, los breves datos sobre ubicaciones de calles y plazas, aparecen sueltos e integrados con tal necesidad en el relato que produce efecto de veracidad y de existencia real de Marineda/La Coruña. Así, la referencia a «la calle del Sol, la calzada que conduce al mar», cercana a la fábrica en el capítulo XXXIV; o «el páramo de Solares en dirección al barrio de Arriba» que cruza Amparo con su amiga en el capítulo XXXVI.

El sistema descriptivo de La Tribuna es muy semejante al de los apuntes funcionales de espacios que aparecen en los diversos relatos conocidos como «Cuentos de Marineda», pertenezcan éstos a la variedad de narrador autobiográfico u omnisciente. De hecho, la lectura del conjunto de los cuentos permitiría hacerse una idea de los espacios principales de la localidad, y de las vidas y voces que resuenan en ellos. Así, conocemos la iglesia que, con todos sus rincones, capillas y corredores es el escenario de la febril peripecia del protagonista en «El rizo del Nazareno», de 1880, que acontece en la noche de un jueves santo. La tienda más antigua de Marineda se describe brevemente en «Las tapias del Campo Santo» de 1881; el narrador considera oportuno dar ciertos detalles, aduciendo el interés que para un observador tendrían su fachada y su abigarrado escaparate. Igualmente, se mencionan, aunque de paso, lugares como el paseo de las Filas, el llamado Coliseo o teatro de ópera, y el Casino de Industriales cuyos bailes eran frecuentados por la juventud. En la humilde casa de una lavandera tiene lugar la terrible escena de violencia doméstica de «El indulto» de 1883, encabezada por un escueto apunte sobre el lavadero público de Marineda en el que transcurría la sacrificada tarea de la protagonista. En «Morrión y Boina», de 1889, la narradora autobiográfica establece el origen del recuerdo que va a relatar en una casa tan concreta como 
la número 16 de la calle de la Angustia, en Marineda. El interior del teatro pomposamente llamado Coliseo, donde se dan sucesivas representaciones de ópera, es el escenario del relato de 1891 «Por el arte», donde un solterón acomodado, trasladado de Madrid a Marineda, cuenta con detalle lo que la agenda musical y el espacio teatral mismo suponían para las relaciones sociales de la clase alta marinedina. Además, el personaje narrador da cuenta de su vida metódica, de la que forma parte su paseo diario por las Filas y calle Mayor, sus salidas al café y al Casino de la Amistad, sólo citados en este relato en función de situar sus hábitos.

En «El doctoral» de 1891 se menciona de paso la Fábrica de Tabacos, y con motivo del desplazamiento del sacerdote para confesar a un agonizante, sabemos de su trayecto por la ancha plaza, las callejuelas del barrio viejo, el descampado del Páramo de Solares, la calle Mayor y el tan mencionado paseo de las Filas marinedino. El relato de 1891 «¿Cobardía?», tal vez el de mayor minuciosidad descriptiva, se ambienta exclusivamente en el lujoso interior del café nuevo de la localidad, que es descrito en detalle por el narrador, uno de los contertulios habituales del local. Por él sabemos también que una de las partes del café fue alquilada en exclusiva para la sociedad llamada popularmente «La Pecera» a causa de las grandes vidrieras del local a dos calles que se especifican con precisión. El narrador es amigo del Mauro Pareja que narra en Memorias de un solterón, y a Mauro lo escucharemos en abundantes discusiones transcritas en estilo directo en este relato.

En definitiva, algunos de los lugares de reunión de la alta clase, el café, el teatro, la iglesia, las viviendas de los barrios humildes que esconden dramas asociados a la pobreza..., que aparecen enfocados individualmente en los relatos, formarán un fresco de la vida total marinedina en la novela La Tribuna y con menor intensidad, en Memorias de un solterón. En cierto sentido, La Tribu$n a$, en su desorden presentativo, sería también la suma de otros varios relatos breves de Marineda, pero aquí orgánicamente unidos a la trama principal que genera Amparo la Tribuna.

No serían esperables en un relato breve largos párrafos descriptivos de escenarios, salvo que éstos tengan importante función para la trama. Pero el lector asiduo de Pardo Bazán recibe en cada texto marinedino apuntes, brochazos de espacios, escenas, voces, fragmentos de vidas que, sumados, permiten en su conjunto adquirir la impresión de una ciudad provinciana real, con sus trayectos urbanos principales, sus viviendas, su plaza, su pretencioso teatro, sus barrios pobres de casas lóbregas, en las que verdaderamente han podido ocurrir esas historias que componen el mosaico de los cuentos marinedinos y las historias de los personajes de La Tribuna. 
La ciudad no sólo es el medio que explica a los personajes de las novelas naturalistas urbanas. Existe una fascinación genuina por la ciudad en los grandes novelistas europeos, algunos de los cuales la consideran emblema de movimiento, de transformación y de modernidad. (López-Landy 94-97). Esto explica el co-protagonismo urbano en las novelas, y la visión de la ciudad como organismo humano y social. Como ha señalado Zubiaurre, Balzac encabeza la lista de escritores realistas para los cuales «la ciudad es un ser que respira y se mueve, un complejo organismo viviente». Balzac trasciende, a su juicio, el mero sistema de clasificación territorial que hace del entorno urbano callejero preciso y verídico, para completarlo con una geografía de carácter ético, a la que no es ajena un procedimiento como el de la personificación de las calles. (Zubiaurre 260-261).

Pensemos en el gran valor y desarrollo que la presentación figurada de una ciudad o uno de sus espacios concretos pueden alcanzar. Archifamosa es la visión primera de esa «heroica ciudad» que dormía la siesta digiriendo «la olla podrida». Y quizás es ejemplo extremo la alegoría que Zola eleva hasta el título en su novela Le ventre de Paris en 1873, obra que propicia algunos de los festines descriptivos más impresionantes de los que guardamos memoria. «El vientre de París» que representa de manera orgánica el gigantesco mercado central de Les Halles, aglutina toda la alimentación -cada uno de los cientos de productos que un mercado puede exhibir- del enorme ente orgánico que es la ciudad de Paris, cuyas calles aparecen también descritas de forma poco denotativa. El lenguaje figurado, las personificaciones y animalizaciones de barrios, calles y casas, cuyo encadenamiento puede llegar a la alegoría, en esta y otras novelas, superponen una carga de permanente juicio de valor añadida al efecto básico de verosimilitud logrado por el mero hecho de nombrar y señalar estructuras urbanas.

\section{LA CARACTERIZACIÓN DE LOS PERSONAJES Y LOS ÍNDICES DE LA PERCEPCIÓN. LA «MIRADA SEMÁNTICA» SOBRE LA CIUDAD}

La descripción tiene que seleccionar, jerarquizar y orientar la mirada en un proceso de descubrimiento. Incluso desde un punto de vista ontológico, ni siquiera literario, la descripción tiene sus raíces en la manera en que vemos el mundo y a los demás. Está tan vinculada al individuo que, para J. Molino, es difícil determinar retóricamente «cuáles son las partes de la descripción de un paisaje», lo que a nuestros efectos sería válido también para el paisaje urbano. La primera persona describiría sólo lo que es importante para él, lo que le impacta o lo que le resulta extraordinario. O bien, con un afán de conocimiento, buscaría toda la información posible acerca de algo, para luego exponer 
ordenadamente su documentación, caso de las «enumeraciones científicas» en Balzac y Zola, según el mismo estudioso. (Molino, 1992:373-379).

Bobes, desarrollando algunas de las famosas propuestas del padre de la teoría moderna de la descripción, Philippe Hamon, explicó muy bien el concepto de «mirada semántica», aplicable a aquellos casos en los que el entorno es captado con la mirada de alguien que le da significado, ya que es frecuente en la gran novela del siglo XIX que los espacios están vinculados a la percepción de los personajes ${ }^{2}$. La «mirada semántica» de la que habla Bobes puede encarnarse en el narrador o en un personaje, pero parece más probable que la descripción encuentre cabida natural y no forzada en la narración novelesca si se asocia a las percepciones de un personaje ad hoc (Bobes Naves, 1985: 213).

Hay que distinguir la especial dificultad del novelista para justificar las descripciones de lugar si el personaje protagonista pertenece a ficciones autobiográficas o a novelas epistolares, por citar sólo dos variedades conflictivas al efecto. El punto de vista narrativo tiene importantes consecuencias sobre la descripción de espacios, y las propias convenciones descriptivas difieren según la perspectiva omnisciente, el estilo indirecto libre u otras formas de focalización interna de los personajes, la ficción autobiográfica, el modelo epistolar, el del relato interior intercalado en una estructura enmarcada, etc. En las novelas de ficción epistolar, los frecuentes comienzos in medias res obligan a los corresponsales -en especial al que abra la novela- a proporcionar la información que tradicionalmente correspondería al narrador en un capítulo inicial de novela: descripción del lugar, información de los antecedentes de lo que acontecerá en el tiempo presente del relato, presentación de personajes. Renunciando el novelista al narrador omnisciente, prescinde también de su típica función presentativa, y ha de esparcir con verosimilitud, mediante la vía epistolar, los datos inaugurales de la ficción.

La conciencia de que las amplias descripciones de escenarios pueden producir cansancio es mayor en los casos de un relato en primera persona y aún más si se trata de simular una narración oral ante un auditorio que podría sentir las descripciones como enemigas de la narración. La descripción detenida de ambientes y espacios, en un contexto de relato oral, puede exasperar a unos narratarios deseosos de «relato»; y por otra parte, se supone que las funciones -y la competencia y habilidad- del ocasional narrador no son tan

2. No es posible referirse aquí a variedades tan relevantes como el espacio recordado, el soñado o el mítico. La crítica ha subrayado, por ejemplo, cómo en ciertas novelas de Balzac, la «mirada interior» puede abolir el espacio o percibirlo de un modo simbólico: el sueño, el sonambulismo, el deseo, propiciarían la capacidad humana de percibir el espacio de un modo personal. (Lozano Sampedro, 2005: 1005-1021). 
amplias como las de un novelista. El justificar la información que se aporta parece especialmente necesario en estos casos de narrador-testigo que cuenta oralmente. Y en todos los contextos, el que un personaje narrador proceda a una descripción demorada de escenarios tiene que motivarse muy bien en el contexto. Así, cuando el narrador autobiográfico de la primera serie de los Episodios galdosianos, Gabriel Araceli, se dispone a contar un momento de importante cambio en su vida (su paso a servir en casa de los Requejos, a fines del capítulo XIV de El 19 de marzo y el 2 de mayo) el capítulo XV ha de empezar con una presentación del nuevo espacio en el que va a transcurrir su vida. Justificadamente en este contexto, el narrador autobiográfico se hace cargo de la misma función presentativa de espacios que cualquier narrador en el comienzo de su relato: «Al punto empecé las indicadas operaciones, cuidando de poner en ellas todo el celo posible para contentar a mis generosos patronos. Debo ante todo dar a conocer la casa en que me encontraba».

Si tomamos la novela de 1875 El escándalo, de Pedro Antonio de Alarcón, que combina la voz narrativa de tercera persona con amplios relatos en primera persona, apreciamos que el capítulo inicial de la novela, significativamente titulado «La opinión pública», es el encargado de ofrecer al lector toda la típica información sobre espacio y personaje. ¿De qué manera? El narrador omnisciente no declina de sus convencionales funciones presentativas, pero una parte de la información inicial queda a cargo de las voces sueltas de amigos y de desconocidos, que asaetean con sus juicios de valor a Fabián en su recorrido por las calles madrileñas a las 3 de la tarde del lunes de carnaval de 1861 .

Una parte fundamental del texto corresponde al relato autobiográfico del arrepentido calavera Fabián, que durante seis horas resume su vida en una «larga relación»o «especie de confesión»-como se califica en distintos lugares de la novela- ante el Padre Paúl que actúa como narratario. La escasa acción presente transcurre en Madrid, y los apuntes espaciales son funcionales y breves, pues no existe el acto del caminar o pasear por la capital. El proceso de reconocimiento y expiación de una vida crápula transcurre en el día y medio que constituye el tiempo presente de la novela, al que luego el Epílogo añadirá un mes para el final feliz del casamiento.

Los breves apuntes espaciales sólo aparecen en función de trazar un itinerario urbano verosímil, sin que los escenarios tengan relieve en la acción ni sirvan a otro fin que la ubicación contemporánea y madrileña de los desplazamientos en coche del protagonista. Fabián, en efecto, visita las viviendas de sus amigos y el convento de los Paúles, lugares en los que desea ajustar urgentemente las cuentas pendientes con su pasado crápula. Se trata de una novela construida sobre la memoria, y en el presente, sobre la confesión discreta y 
el diálogo liberador de la culpa, por lo que la ubicación de los coloquios en interiores es predominante. Si aparecen otros escenarios será en función de contraponer al presente los lugares donde el protagonista acudía en sus tiempos de vida amoral. Así, en Libro V, II, el café de Daoiz y Velarde del barrio del Avapiés, lugar de reunión de la mala vida madrileña.

Incluso después de la eclosión naturalista, la opción narrativa de la ficción autobiográfica en las Memorias de un solterón de Pardo Bazán (1891), excluye la posibilidad de la amplia descripción urbana, debido al tipo de personaje al que se le atribuye la redacción de sus Memorias. En efecto, no podremos esperar de un personaje introspectivo y meditativo como es el solterón del título más que apuntes descriptivos sumarios, asociados a sus escasas salidas al exterior y recorridos por las calles. El predominio de interiores domésticos en los que transcurre su vida, y las reuniones sociales a las que se suma el Mauro Parejo que narra, convierten en puramente funcionales (trasladarse de un sitio a otro) sus trayectos urbanos. No existe descripción de Marineda ni de ambientes en los primeros capítulos; al narrador sólo le interesa, además de ofrecer su autorretrato, recopilar gran número de apuntes sobre su mundo: los personajes con los que se relaciona, sus amigos, las hijas de Neira, sagazmente descritas desde la perspectiva de un varón maduro y casadero.

La atípica Feíta Neira, su amiga, sería el tipo de personaje ideal para mostrar la vida urbana: sus salidas continuas, su libertad y callejeo, su curiosidad, la convierten en el punto de vista ideal para la descripción. Pero al tratarse de un relato en primera persona, el narrador no omnisciente no puede seguirla ni escudarse en el punto de vista de la joven. Así pues, la mirada de Feíta no será útil a los efectos de la descripción urbana.

En el capítulo XXII el solterón narrador se dirige al lector presuponiendo su cansancio al avanzar poco en la intriga de una historia: «hasta este momento nada ocurre de eso que la gente llama sucesos dramáticos». Declara entonces su voluntad de «imitar a los novelistas», entendiendo por esto el cambio en ese punto a la narrativa omnisciente, lo que le permitirá reproducir abundantemente las reflexiones directas de Baltasar Sobrado sobre las pretensiones del hijo natural que tuvo con Amparo La Tribuna. Sin embargo, el trasvase a la perspectiva omnisciente no conlleva una mayor «gestión» de la topografía urbana. El lector hallará sólo breve apuntes de trayectos por la plaza mayor, de la llamada Pecera o especie de casino donde acude ocasionalmente y desde cuyas ventanas mira a la gente...

Muy cerca ya del modelo de personaje modernista, el ensimismado narrador autobiográfico de La sirena negra de Pardo Bazán, en 1898 oscila entre el continuo autoanálisis («esas conversaciones interiores, en que dialoga mi 
doble yo», como las denomina en capítulo XVIII) y la frecuente transcripción de sus conversaciones, de tal modo que son casi inexistentes las descripciones de los espacios exteriores e interiores de Madrid. El narrador protagonista, Gaspar de Montenegro, tipo del personaje decadente y estragado tan frecuente en el modernismo, se define en el capítulo inicial como perteneciente al grupo de «los meditativos sensuales». La vida en la capital no le inspira la menor interacción con el entorno, y sólo la naturaleza, el campo y el mar-durante el verano en un lugar balneario cercano a Vigo- generan descripciones tamizadas por un cambio crucial en su vida.

El narrador autobiográfico no suele adoptar las premisas de orden narrativo comunes en el omnisciente, ya que no tiene que componer una novela, por así decir, sino que un motivo personal (un caso) le impulsa a «meterse a narrador». Esta es la razón de que el inicio de La sirena negra simule que por azar se reproduce una parte de un amplio monólogo del narrador, quien literalmente habla «para su sayo»:

En la esquina de la Red de San Luis y el de Gracia, me separé del grupo que venía conmigo desde el teatro de Apolo, donde acabábamos de asistir a un estreno afortunado. Si hablase en alta voz, hubiese dicho "grupo de amigos», pero, para mi sayo, ¿qué necesidad tengo de edulcorar la infusión [...]?

No tendrían sentido en esta ficción autobiográfica las convenciones de un narrador omnisciente obligado a presentar el espacio, especificar el cuándo y finalmente presentar al personaje principal, que aquí ya tenemos delante desde el principio. El egocéntrico protagonista deja claro al inicio del relato que la introspección, uno de los rasgos más definitorios de su personalidad, es contraria a la capacidad de salir de sí mismo y de «ver» el entorno, previas al acto de describir.

Inoportuno sería también describir sin objeto, sin un destinatario (el lector implícito o bien un interlocutor en la diégesis narrativa) para el cual elaborar con pertinencia la información descriptiva. Por ello se hace preciso justificar los apuntes de percepción sensorial del espacio que -y esto sí, según la tradición narrativa- suelen figurar en los capítulos de apertura, aunque en la novela que comentamos se entremezclan las escasas observaciones exteriores del espacio con las abstracciones en las que el personaje suele zambullirse enseguida.

Es evidente que el ensimismamiento está reñido con la atención curiosa hacia el exterior, tanto que Ángel Ganivet en Los infatigables trabajos de Pío Cid, por las mismas fechas que la novela de Pardo Bazán antes citada, hace que su narrador se disculpe ante el lector por la ausencia de descripciones de los paisajes que recorre el protagonista, argumentando que la introspección es 
característica contraria al arte de la descripción. Cuando Pío Cid se encamina al domicilio de la duquesa, su actitud reflexiva impide que se fije en el paisaje. Así lo comenta el narrador, y justifica la pertinencia de sus explicaciones:

Y no está de más esta explicación, pues seguramente no faltará quien me censure por no hallar en este relato ninguna descripción de los lugares por donde fue pasando mi héroe, siendo así que yo he debido atenerme a la verdad, y la verdad es que él no hizo consideraciones de ninguna especie sobre los terrenos que iba pisando. (Ganivet, 1983:334)

Por razones equiparables, las dos novelas de Ramón Pérez de Ayala Tigre Juan y El curandero de su honra (1925) que trataremos en el epígrafe final de este recorrido, incluyen tan mínimos apuntes -y éstos, escenario funcional aunque repleto de connotaciones- acerca de los espacios.

Si tomamos como motivo novelesco el de la itinerancia del personaje que llega de nuevas a una ciudad, sí que encontraremos en principio un contexto excelente para las descripciones urbanas. El lector conocerá la ciudad desde el punto de vista del personaje y según sus criterios de selección. Como señalaba Mesonero en su «Paseo por las calles» ya en 1835: «Nada más natural en un forastero que la curiosidad de conocer el aspecto general del pueblo que por primera vez visita». (Mesonero Romanos, 1993: 215).

Si el espacio real se ofrece al lector como registro de las observaciones del viajero, la subjetividad atribuida a la selección de la información es inevitable, y ello nos indicará mucho sobre la individualidad del personaje. Pero no sólo hay que hablar del personaje viajero que observa como novedad el entorno al que se desplaza. Cualquier lector puede notar también la funcionalidad de centenares de trayectos de personajes locales que abren los ojos a escenarios a veces desconocidos de su propia ciudad. Así, En Fortunata y Jacinta, una parte de las descripciones de espacio está vinculada a los recorridos urbanos de los personajes, y a su capacidad de observación, voluble y dependiente siempre de un estado de ánimo eventualmente expansivo o retraído. En palabras de López-Landy, en las novelas contemporáneas de Galdós -señeramente en Fortunata y Jacinta- las casas, calles y barrios madrileños añaden una atmósfera asociada estrechamente a la personalidad de los personajes, además de corresponderse con itinerarios absolutamente reales. (López-Landy, 1979: 16).

Memorable a este respecto es la viva descripción de la calle de Toledo con sus puestos abigarrados, que abre el capítulo IX, i de la Primera Parte de Fortunata y Jacinta. La percepción asombrada y aturdida de Jacinta, desconocedora de los espacios en los que habita «el cuarto estado» madrileño justifica tal despliegue descriptivo. El recorrido a pie de Jacinta y Guillermina las va (y nos va) aproximando desde una primera panorámica, hasta llegar a 
la apertura de IX, ii, centrada ya en la descripción de la corrala y de la vida bullente que contiene, con sus corredores y túneles, su patio, la vista general de las casas e incluso de los tejados («echando una mirada a lo alto del tejado, vio la Delfina...»), para alcanzar al objeto final de todo el recorrido, el habitáculo de la familia de Ido del Sagrario.

El detallismo de la observación y la consecuente descripción es siempre variable, y por supuesto, el estilo indirecto libre, así como los continuos índices de percepción que jalonan el texto (x vio..., x observó...) son opciones recurrentes para describir desde los ojos y sensaciones del personaje.

La curiosidad del niño que llega a Madrid procedente de su pueblo norteño en El doctor Centeno galdosiano, explicará una primera panorámica urbana, seleccionada en consonancia con su asombro y su perspectiva sobre las proporciones de lo que contempla. A través de sus ojos, y en estilo indirecto libre, conocemos a un tiempo las vistas desde el exterior de Madrid, la estación, la mole del hospital, la «casona Grande» que luego sabremos que es el Observatorio madrileño... Y en adelante, buena parte del Madrid urbano se nos mostrará según «Felipe veía», «Felipe observaba». (Román Román, 2008b:24-26).

Por las mismas fechas de la novela galdosiana recién citada, 1883, Zola iniciaba igualmente Au bonheur des dames con la llegada a París de tres hermanas huérfanas, procedentes de una ciudad de provincias. Desde la estación los personajes recorren a pie, con curiosidad asombrada, las calles de la capital mientras buscan la casa de su pariente en la ciudad. El cansancio del hermano pequeño, que puede reflejarse en el de algunos lectores ante el detallismo del recorrido, no impide que la mayor se detenga con ojos muy abiertos ante el escaparate de la tienda que da título a la novela, descrita entonces con todo detalle, desde la visión subjetiva de la joven.

En general, la figura del recién llegado a la ciudad suele ser especialmente productiva para la presentación de las estructuras urbanas, salvo que se trate de un tipo de personaje abstraído, como ocurre con la ya mencionada doña Berta de Clarín (1892), cuya sordera y costumbres la aíslan del mundo -según leemos en capítulo $\mathrm{X}$ - pese a lo cual «doña Berta iba y venía, atravesando los peligros de las ruedas de los coches y de los cascos de los caballos; cada vez más aturdida, más débil... y más empeñada en su imposible». Sus trayectos se precisan en simultaneidad a la transcripción directa de sus pensamientos mientras recorre un Madrid perfectamente reconocible en su detallado callejero, aunque sin la demora descriptiva de espacios y escenas que correspondería en otro modelo de personaje. 
A diferencia de las ciudades pequeñas o provincianas, la extensión de una capital tiene especiales requerimientos, para los cuales es aún más necesario el personaje paseante, el flâneur que sin objetivo exacto, sin prisas, permita la descripción. Las novelas de estudiante, las de artista, las iniciáticas o de aprendizaje son terreno propicio para el recorrido urbano. No es raro que hayan llamado la atención de la crítica ciertos personajes peripatéticos, muy funcionales para la descripción del espacio exterior, como los creados por Galdós asiduamente: el Frasquito Ponte que en Misericordia se mueve por los barrios pobres del Sur, evitando el Centro y el Norte para ocultar su descenso social, o la Nina protagonista de la novela, nos permiten acercarnos a escenarios infrecuentes en la narrativa de Galdós, como las casas de vecindad, las llamadas casas de dormir, las rondas de la periferia urbana... (Sádaba Alonso, 2001-2002: 63-80).

El Luisito de Miau, Felipín y Alejandro Miquis en El doctor Centeno, pertenecen a la amplia nómina de personajes que entran y salen desde los espacios interiores y domésticos, y cuyo incansable vagar permite la presentación de decenas de calles, plazas, iglesias, cafés y otros lugares de ocio, junto a la vida humana que hierve en ellos. Como el estudiante Miquis que llega de La Mancha a la capital en El doctor Centeno, el estudiante Rastignac balzaciano es especialmente provechoso para el conocimiento de Paris, dentro del heterogéneo grupo de pupilos que llegan a la pensión de la señora Vauquer, cuya famosa descripción abre Le Pére Goriot. La capital francesa se muestra al lector mediante el recorrido iniciático del joven de provincias, función que en la novela galdosiana se reparte entre Felipe Centeno y su amo el estudiante.

Por último, las salidas y trayectos de los personajes, con sus peculiares motivaciones y su actitud en los recorridos, son también un elemento importante para su caracterización, como propone F. Anderson acerca del cambio en los recorridos que Villaamil realiza en Miau, y que son índice de su toma de conciencia, de su enloquecimiento progresivo, de su rechazo a la opresión doméstica y de su liberación final. (Anderson, 1993: 23-29).

\section{LA CONVENCIÓN DEL INICIO DE LA NOVELA COMO LUGAR PRIVILEGIADO PARA LA DESCRIPCIÓN ESPACIAL. LA CREACIÓN DE LA PANORÁMICA}

Desde el punto de vista narratológico, el espacio puede aparecer en las pausas narrativas, cuando la acción se interrumpe y el tiempo queda suspendido mediante las descripciones espaciales, las digresiones y excursos, etc. Pero si el arranque de la novela se dedica a la descripción demorada de escenarios, algunos críticos y los propios novelistas en eventuales reflexiones metaliterarias, 
reconocen el riesgo de defraudar las expectativas de un lector impaciente que espera anécdota, hechos. La descripción, entonces, puede ser vista como enemiga de la narración.

Algunos estudios de la novela han destacado la importancia de los inicios de las novelas, entendiendo que tienen una función informativa esencial, la de enunciar los objetos, personas, lugares y tiempos que el novelista se propone poner en juego en adelante. Para Grivel, las novelas que atrapan el interés del lector suelen introducir ya en las primeras líneas las localizaciones, más o menos precisas, pues señalar el espacio añade consistencia y veracidad. Pero si el novelista se desboca en el detallismo excesivo en las descripciones de apertura, está demorando el inicio del relato, ya que mientras más información se nos dé de los espacios, menos -o nada- sabemos aún de los hechos. En palabras de Grivel, «tout savoir du lieu c'est encore rien savoir (en fait) de l'événement». (Grivel, 1973: 104). A cambio, un aspecto paradójicamente positivo para el realismo de la novela es que aunque la acumulación descriptiva resulte contraria a la narración, mientras más detalles se den sobre un lugar, más comprobable o verificable será en la realidad, y el lector podría hipotéticamente buscar en la realidad una casa concreta en una calle de tal ciudad. Todos los datos que se dan para precisar la localización inicial y sucesiva de los hechos responden a la necesidad de presentarlos como verídicos, y son los datos espaciales los que definen al texto como imagen mimética de algo. (Grivel, 1973: 91-93 y 104-106).

En los relatos omniscientes, las grandes descripciones espaciales tienden a situarse en las aperturas. Si se asocian al punto de vista de un personaje, se añaden también -o a cambio- en otros momentos en la novela, como pinceladas bien trabadas y motivadas por la experiencia del personaje.

De todas maneras, es preciso diseminar con oportunidad y mesura las descripciones, advierte Zola, para quien la práctica de los Goncourt y de Flaubert era preferible a la de las amplias descripciones que solían abrir las novelas de Balzac. Estas aperturas balzacianas, en su opinión, eran desaconsejables ya que obstaculizaban el relato. (Zola, 1989: 39).

Si por nuestra parte volvemos al inicio de Le Pére Goriot comprobaremos cómo en su combinación de teoría y práctica de la descripción, una detallada parte se dedica a la descripción de la calle Neuve-Sainte-Geneviève en la que se ubica la pensión burguesa de la señora Vauquer. Las minuciosas especificaciones espaciales (a izquierda, a derecha, a lo largo de, enfrente de...) tienen un efecto deíctico y crean la ilusión de que en cualquier momento, pertrechado con ese plano, el lector puede dirigirse al lugar y verlo con sus propios ojos. Pero además, el novelista justifica su tarea aclarando que el detallismo 
sobre la calle es proporcional a la función de la misma en la novela, que Balzac compara a un marco de bronce que enmarcará adecuadamente el relato.

El inicio del texto puede dar el tono de la novela, como la obertura a una ópera. Incluso si un espacio no va a ser el escenario principal, el honor de abrir la novela lo recibe por una razón poderosa, la de dar el tono del relato. Así, la descripción burlona de «un gallardo artificio sepulcral de atrevidísima arquitectura, grandioso de traza, en ornamentos rico, por una parte severo y rectilíneo a la manera viñolesca, por otra movido, ondulante y quebradizo a la usanza gótica, con ciertos atisbos platerescos donde menos se pensaba...» que da inicio a La de Bringas de Galdós, sorprende al lector para enfrentarlo enseguida al contraste entre apariencia-realidad que esta novela de la hipocresía social va a ejemplificar una y otra vez, como explicó lúcidamente R. Russell (1993: 817-822).

Recuérdese también la potente descripción de la iglesia de San Sebastián en la apertura de Misericordia de Galdós, la cual aun no siendo el escenario esencial de la novela, revela el protagonismo de la iglesia en las vidas del esforzado ejército de los pobres madrileños. Al mismo tiempo, el malicioso lenguaje figurado de la descripción subraya la «doble cara» de la iglesia y encabeza el gran asunto de la hipocresía social y de las dobles caras de numerosos personajes que en adelante irán apareciendo en la novela. (Sádaba Alonso, 2001-2002: 63-80).

Asunto muy distinto es que un determinado tipo de lector se exaspere con tal detallismo espacial, cuando tal vez se conformaría con las coordenadas básicas de lugar y tiempo. Barthes cree que a Flaubert se le lee de una forma diferente que a los relatos más clásicos de Balzac, Dickens, Zola o Tolstoi. $\mathrm{Su}$ argumento es que el exagerado detallismo de éstos provoca que muchos lectores los afronten sin el menor reparo de saltarse pasajes que les parecen aburridos («las descripciones, las consideraciones...») con el fin de «reencontrar lo más rápido posible los lugares quemantes de la anécdota (que son siempre sus articulaciones: lo que hace avanzar el desvelamiento del enigma o del destino» (Barthes, 1974: 18-19). Sean cuales sean los razonamientos sobre la actitud de los lectores ante la descripción, lo que parece fuera de duda es la conciencia del novelista sobre la importancia de los arranques de los relatos, asunto que retomaremos en el epígrafe final con la intención de mostrar la reacción de las novelas intelectuales contra las convenciones del detallismo espacial en las aperturas de las novelas. 


\section{PARADIGMAS DE LA DESCRIPCIÓN. EL AGOTAMIENTO DEL MODELO DEL NARRADOR-GUÍA. EL AGOTAMIENTO DEL MODELO DE LAS APERTURAS PRESENTATIVAS. LA DESCRIPCIÓN PANORÁMICA Y SU SUBVERSIÓN}

Las visiones panorámicas de espacios eran ya propias del observador costumbrista, y tenían estrecha relación con la dialéctica y hasta la confusión entre descripción y narración en los cuadros de costumbres, como bien apuntó José Escobar. El estudioso del costumbrismo ya subrayó esa perspectiva, tan común en muchos artículos, del paseante mirón que va y viene por la ciudad, y anota -a menudo con unas primeras visiones panorámicas- lo que ven sus ojos, y a veces lo que oye (Escobar, 1988: 53-60).

A los lectores de artículos de costumbres les resulta muy familiar ese modelo del figurado "guía» que, al frente del nutrido grupo de lectores, los lleva y los trae por los escenarios de la contemplación, dirigiendo a su antojo el periplo. Se trata de una estructura que representa muy bien el artículo de Mesonero Romanos «Paseo por las calles» de 1835 incluido en Escenas y tipos matritenses. El imaginario paseo propone a los lectores un itinerario con el periodista como guía que anima a sus lectores («vedla», «sigamos, por ejemplo, a alguna de esas parejas...») seleccionando ante sus ojos algunos detalles del recorrido, y también los tipos y escenas que, como al azar, se encuentran en el camino (Mesonero, 1993: 226 y 228).

Por lo que respecta a las novelas históricas del Romanticismo, el desorden cronológico y los continuos saltos de lugar en ellas eran consecuencia del laberinto argumental propio del género, tan bien explicado por R. P. Sebold. Como el narrador debe atender a dos o más historias que se desarrollan simultáneamente en lugares muy diversos, tiene que apresurarse en transportarse de unos lugares a otros, y a menudo comparte con los lectores su agitación y sus dificultades, en una actitud de complicidad muy propia de la novela popular (Sebold, 2002:40-50).

¿En qué momento comienza a apreciarse un cansancio de la convención del «recorrido con guía» y del paradigma descriptivo de la panorámica? No es ociosa la pregunta, ya que la parodia, las balizas metaliterarias en el propio texto, la contrafactura, la subversión del paradigma, aparecerán para manifestar la distancia irónica respecto a los moldes consolidados.

El paso desde esta complicidad hasta la distancia humorística ante el trasiego espacial del narrador-guía ya está inserto en las propias novelas históricas. En la novela de Escosura Estudios históricos sobre las costumbres españolas, de 1851, uno de los narradores orales de relatos históricos, en el contexto de la tertulia que enmarca y articula parte de la novela, se hace eco jocoso de lo 
que le parecía convención descriptiva, la del narrador-guía tan usual en decenas de artículos costumbristas y en la novela popular. Para el citado narrador oral de Escosura se trataba ya de un recurso muy trillado del cual toma distancia -aun sin poder abandonarlo- mediante el comentario metanovelesco:

¡oh, si yo fuera uno de aquellos bienaventurados narradores cuyo talento descriptivo extiende, deslíe y, por decirlo así, disuelve los sucesos, en un mar de entretenidos pormenores! Entonces me los llevaría a ustedes, mis caros oyentes, como por la mano a la casa del cura [...] (Escosura, 1851: 18).

En el mismo año de la novela de Escosura, Carolina Coronado hace explícito en algunas de sus novelas que conoce bien la tradición de abrir el relato con las coordenadas de espacio y de tiempo y la presentación de los personajes principales. En efecto, su novela Luz se abre informando de que la acción principal se da en Sevilla en 1836, y mostrando desde el primer capítulo los espacios de palacios andaluces y ambientes y personajes aristocráticos. Y sin embargo, la expectativa del narrador-guía en las descripciones de ambientes específicos, ya dentro de cada capítulo, produce a la autora un eventual cansancio que comparte con sus lectores, como cuando el capítulo V de Luz afronta con humor expeditivo el «deber» del detallismo espacial:

Qué calles cruzó para llegar a su casa, ni nos hemos tomado la molestia de observarlo, ni ofrece interés al lector, bastándole con saber que llegó en efecto y que entró en su habitación, cómoda, como debe serlo la de un canónigo (Coronado, 1999b: 57-58)

De manera desenvuelta, la autora se desembaraza de algunos de sus deberes, dejando al mismo tiempo en el texto la constancia de que los conoce. Sabemos bien que la complicidad con los lectores es común en las novelas populares y en las históricas; pero 1851 resulta una fecha temprana para cuestionar explícitamente las convenciones descriptivas, optando además por la reticencia. (Román Román, 2011).

Consciente la novelista de que el lector espera conocer el lugar donde vivía la protagonista, tiene que hacerse perdonar por sus renuencias descriptivas, como notamos en el siguiente pasaje de su novela La Sigea, aún en 1851:

las ventanas del pabellón que habita la escritora de Toledo, dan sobre el jardín real, y mis lectores naturalmente querrán saber cómo es este jardín. Esto es muy justo. Desde que el primer escritor dio a su lector el adjetivo de curioso, ha sido curioso siempre y seguirá siéndolo mientras haya escritores (Coronado, 1999a: 403-404)

Las novelas de escenario urbano suelen describir ordenadamente, comenzando mediante la vista desde lo alto (a veces con el detallismo y selección posterior que permite el catalejo) que permite una primera visión panorámica 
casi cinematográfica, en la que luego la cámara se acerca a un barrio, a una calle, y finalmente, a la casa o el edificio donde el protagonista principal habita. La vista desde lo alto, en efecto, es uno de los clásicos «modelos mentales» para representar un espacio, también desde el ámbito de la iconografía clásica de las ciudades. Como explica Cesare de Seta, la vista desde lo alto permite una mirada orgánica de síntesis. Ese punto de vista que miniaturiza lo percibido a vista de pájaro, ordena y comprehende, toma posesión del espacio para conocerlo, dominarlo y proyectarlo, aunque sea modificado, como consecuencia de la necesidad de representarlo de un modo verosímil (Seta, 2011: 27-30).

Muchas novelas del XIX evitan presentar una imagen del caos urbano, y para ello es muy útil la función del panorama, que enmarca y permite conocer ordenadamente la ciudad. El callejero y las indicaciones espaciales de todo tipo, prueban una voluntad de verosimilitud y también el deseo de trazar una especie de guía urbana que contribuya a presentar una visión ordenada de los escenarios (Zubiaurre, 2000: 231). A ello añadimos por nuestra parte que en algún momento el personaje puede sentir que la ciudad es un laberinto, puede perderse real o figuradamente en sus calles o en el magma de las relaciones sociales. La propia metáfora del laberinto aparece a menudo, manifestando cómo un personaje percibe la ciudad o una parte de ella, y ya Mesonero se refería a la agitación de la Puerta del Sol, calles adyacentes y trayecto hasta el Paseo del Prado como «laberinto» del que se puede salir marchando hacia la Calle Ancha entre otras (Mesonero, 1993: 225).

Es el caso de cómo la protagonista de Doña Berta (capítulo VI) anticipa Madrid, desde su miedo a la novedad y al agotador trayecto desde su lugar rural a la capital: «ella misma necesitaba de todo su valor, de su resolución inquebrantable, para salir de su casa y meterse en aquel laberinto de caminos, de pueblos, de ruido y de gentes extrañas, enemigas».

Un paisaje, una visión de una ciudad desde un promontorio, se ven de golpe, pero en literatura hay que dotar de un orden sucesivo a la presentación. Algunos ejemplos nos permitirán reconocer cómo se asienta la «poética» de la descripción panorámica. En el capítulo inicial de La familia de Alvareda, 1849, Fernán Caballero construye una típica descripción panorámica en la que se van destacando con precisión onomástica y espacial los caminos que deben seguir imaginariamente los ojos para reconstruir el escenario, en principio mostrado a vista de pájaro desde las ruinas del castillo de San Fernando, y luego con perspectiva descendente. El narrador articula y organiza su descripción mediante el conocido papel de guía de una caminata o expedición de reconocimiento, en la que le acompañan sus lectores: «Mas prosigamos la 
marcha del camino, que adelanta abriéndose paso por entre los palmitos y las carrascas de una dehesa hasta penetrar en el lugar de Dos Hermanas que se halla asentado en un llano arenoso, a dos leguas de Sevilla».

Llegado a este punto de la ruta iniciada a las afueras de Sevilla, el lector se encontrará un panorama urbano de la trama de las calles, hasta llegar a la plaza; en ella, a la iglesia, y enseguida, a la casa del sacristán. A ello seguirá la precisa coordenada temporal ( «a la caída de una hermosa tarde de enero del año 1810») y la primera aparición de la figura humana en este decorado ( «hubiese podido oírse la sonora y fresca voz de un joven como de veinte años que, con la escopeta al hombro, caminaba con paso firme y ligero por una de las veredas trazadas en los olivares»). Cuando por último se ofrece el retrato del personaje, tendremos ya una cumplida muestra de modelo de apertura frecuentísimo en la narrativa del siglo XIX.

Si confrontamos la apertura (Primera parte, capítulo I) de Gloria de Galdós con la que Ramón Pérez de Ayala realizará en Belarmino y Apolonio, como haremos más adelante, tendremos buena muestra del contraste entre un típico modelo descriptivo decimonónico y la contrafactura de este modelo. El título del capítulo galdosiano, «Arriba el telón», implica la necesidad de la presentación de un escenario para el espectáculo que vamos a presenciar. En primer lugar se ofrece una visión panorámica de la ciudad costera de Ficóbriga; desde lo alto, el narrador encabeza una caminata que pretende llevar a los lectores desde los campos exteriores hasta la localidad. Aunque la villa «no ha de buscarse en la Geografía sino en el mapa moral de España», el narrador se vale de las explicaciones y de numerosos deícticos para que visualicemos plásticamente el lugar, y como guía anima la expedición en un locus amoenus, («marchemos», «estamos cerca y podemos verlo», «iHermoso espectáculo ofrecen desde aquí las montañas...!»), además de describir poco a poco cada detalle del apacible paseo en un "claro día», de «Junio, mes encantador en esta comarca costera $[\ldots] »$, que contrastará finalmente con el aspecto de las primeras casas, viejas y destartaladas, de la villa.

El amplio decorado inicial debe presentar la ciudad o pueblo en el que transcurrirá la acción, y luego se irá precisando en sucesivos zooms desde la panorámica inicial, hasta llegar a las calles, paseos, lugares de reunión, casas concretas donde habitan los protagonistas, y finalmente, la casa en la que dará comienzo la historia: «En la plazoleta (miradla bien, porque ahora comienza nuestra historia) está una casa...»

Cuando aparezca la narrativa «intelectual» del siglo XX, la vanguardia tendrá en cuenta este modelo para crear sobre sus pautas, aun contrahaciéndolas 
por diversos procedimientos, que recordamos a continuación, en el epígrafe final de nuestro recorrido.

\section{LA CONTRAFACTURA DE LAS CONVENCIONES DESCRIPTIVAS EN RAMÓN GÓMEZ DE LA SERNA Y RAMÓN PÉREZ DE AYALA}

¿Las descripciones detalladas son en verdad contrarias a la narración pura de acontecimientos que tanto agrada a la mayoría de lectores de novela realista? Los narradores declaran a veces su conciencia de que así es. Es cierto que existen enclaves descriptivos tan plagados de datos, que el novelista suaviza su mala conciencia justificándose por la impaciencia que puede causar tal documentación. Como ha visto la crítica, el novelista del siglo XIX no renuncia a la tentación de incorporar -sobre todo en los enclaves descriptivos- la documentación que ha acumulado en sus búsquedas de información preparatorias de las novelas. Para algún estudioso, la descripción es lugar preferente para incorporar el discurso documental a la novela, que cumple además las funciones narrativas de fijar los conocimientos sobre el espacio y los personajes, aportar datos de ambiente, añadir intriga al relato demorando la narración en momentos cruciales, entre otras. (Zubiaurre, 2000: 44-45).

Para E. Baker, el Madrid que presenta Ayguals de Yzco en sus folletines es frecuentemente «un simple trasunto de los Manuales de Mesonero y de otras obras por el estilo» al modo de las guías de forasteros. Y en el caso de Fernán, la Sevilla que aparece en sus novelas «no pasa de ser una serie de tarjetas postales -la catedral, la Giralda-» que representan el pasado estático (Baker, 1991: 92-93). Así pues, la documentación acarreada en dos modelos narrativos tan distintos sería un factor común en sus descripciones urbanas.

Buen ejemplo de la mala conciencia ante el eventual exceso documental de la descripción lo encontramos de nuevo en los citados Estudios históricos sobre las costumbres españolas de Patricio de la Escosura, donde el narrador anticipa el tedio que va a producir su profusa descripción -repleta de detalles arquitectónicos y decorativos- del edificio del regente de la audiencia madrileña. Como no va a renunciar de ningún modo a tal perorata, más temible aún al tratarse de un relato oral, anticipa a sus oyentes: «duérmase el que de oírme se canse» (Escosura, 1851: 48-49).

El comentario metaliterario sobre la descripción, e incluso una reticencia jocosa pueden ser vías para presuponer el efecto de hastío de una descripción demorada. Es el caso de la que, tras anunciarse en forma de acotación, pasa a omitirse flagrantemente en la voz de Agustín como posible narrador primera persona, «no novelista», en el capítulo XXV de Tormento de Galdós. Se reduce a breve acotación lo que habría sido una descripción de lugares de Burdeos 
consagrados por la experiencia viajera. El narrador omnisciente se comporta como oyente implícitamente hastiado de la conversación entre la pareja formada por Amparo y su enamorado Agustín, conversación que ha reproducido desarticulada y fragmentariamente-además de en estilo indirecto libre-como prueba de distancia irónica ante lo que tiene que oír; entre otras cosas, la supuesta descripción que decide omitir:

A él le daba por tener buenos vinos en su bodega. Sobre todo, de las famosas marcas de Burdeos no se le escaparía ninguna. ¿Y era Burdeos bonito? ¡Oh!, precioso. (Descripción de los Quinconces, del puerto, de la Allée de l'Intendence, de la Croix Blanche y de los amenos contornos llenos de hermosas viñas). A esta ciudad tranquila, que parece corte por la suntuosidad de sus edificios, sin que haya en ella el tumulto ni las locuras de París, irían los esposos a pasar una temporadita.

Un autor y crítico tan fino como Clarín, ya advirtió en una «Revista literaria» de 1891 cómo las descripciones detalladas podían ser contrarias a los intereses de los lectores. A propósito de la minuciosidad descriptiva de Toledo en la novela galdosiana Angel Guerra, Clarín valora que las descripciones ayudan a explicar el misticismo activo y la psicología del protagonista, siempre alentado por lo sensible. Pese a todo, advierte que tanto el exceso de personajes como el exceso descriptivo de esta novela galdosiana pueden cansar al lector. (Román Román, 2010: 100)

En 1929, en su «Primer manifiesto del Surrealismo», André Breton razonaba su horror por la estética realista, que encontraba su reino literario en las novelas basadas en la observación del entorno. Particularmente le indignaban las descripciones con las que suelen abrirse las novelas, y de las que afirma que lo inducían a cerrar rápidamente el libro:

¿y las descripciones! En cuanto a vaciedad, nada hay que se les pueda comparar; no son más que superposiciones de imágenes de catálogo, de las que el autor se sirve sin limitación alguna, y aprovecha la ocasión para poner bajo mi vista sus tarjetas postales, buscando que juntamente con él fije mi atención en los lugares comunes que me ofrece!

Tras proponer un ejemplo de un fragmento descriptivo de interior doméstico burgués en Crimen y castigo de Dostoievski, lo ridiculiza y concluye: «Permitidme que me salte la descripción arriba reproducida, así como muchas otras.» (Breton, 1992: 22-23).

Recordemos que mucho antes, en una fecha tan temprana como 1912, algunas obras españolas enfrentaban al típico lector de novela realista con un nuevo modelo que suponía una rotunda ruptura de las expectativas consolidadas por un cierto tipo de novela. Un lector de contenidos podría exasperarse, por poner un ejemplo, con un capítulo tan lento y heterogéneo como el 
VI de la primera parte de La pata de la raposa de Pérez de Ayala, compuesto de notas sueltas, a modo de collage o album personal del protagonista, con apuntes de lecturas, con sus pensamientos propios. El aristócrata protagonista podría tener algo en común con el de La sirena negra de Pardo Bazán. Pero ahora, abúlico y ocioso, anota minucias cotidianas fruto de su observación: sus animales domésticos, un hormiguero en la huerta... en una actitud que guarda paralelismo con la que hallaremos en Oceanografía del tedio de D' Ors en 1921, obra bien ajena al concepto «novela». El personaje artista, creativo y eventual escritor es el protagonista ideal de este tipo de novelas, algunas de las cuales la crítica ha calificado como «intelectuales», en las que además se hace presente un tratamiento irónico de los recursos narrativos convencionales (Amorós, 1970: 26-28).

Frente a tanto experimento narrativo resulta en principio desconcertante la imitación -menos desconcertante si la consideramos parodia- que realiza Ayala de la apertura de La Regenta en La Pata de la raposa:

Pilares, la decrépita ciudad, centenario asilo de monotonía y silencio, yacía al sol poniente, más callada y absorta que nunca. De vez en cuando, la voz medioeval e imperecedera de las campañas, sacudía, como errante escalofrío, la modorra de aquel pétreo organismo. La ciudad parecía respirar un vaho rojizo y grave [...]»(Pérez de Ayala, 1970: 39).

A lo anterior, y a modo de travelling, seguirá la aproximación a la calle de Jovellanos, hasta enfocar una casa en la que una joven se asoma a un balcón, momento en el que se inicia una escena entre dos personajes.

La descripción de Pilares/Oviedo es por completo prescindible, salvo tal vez en lo referido a la silenciosa calle burguesa en la que se ubica la casa del protagonista, según $\mathrm{M}^{a}$ Dolores Albiac. A su juicio, ni en los exteriores ni en los barrios ni calles sucede nada trascendental para el relato de Ayala, novela de interiores en la que la ciudad no tiene la función simbólica ni alegórica de La Regenta. ¿Por qué Ayala comienza con una descripción de la ciudad sobre la pauta de Clarín, si lo que le interesa es el mundo interior de un intelectual abúlico, en un periodo especialmente crítico de su vida? Buena pregunta, a la que Albiac no encuentra otra respuesta que la inmensa admiración de Ayala por su maestro y antiguo profesor ovetense. (Albiac, 2001: 123-125).

Es posible que otra respuesta esté en la evolución de la propia obra de Ayala: sin abandonar definitivamente el influjo de La Regenta, en 1920 el autor cuestiona de forma teórica y práctica los modos descriptivos de la ciudad en la novela clariniana y por extensión en otras novelas decimonónicas. Es Belarmino y Apolonio la novela que, manteniendo el mismo espacio urbano de la ficticia Pilares trasunto de Oviedo, construye y destruye a un tiempo la 
tradicional panorámica urbana con la que tantas novelas decimonónicas se iniciaban.

En Belarmino y Apolonio, la atípica descripción del escenario principal de la novela no aparece hasta el capítulo II, textualmente muy tardío ya que sigue a un largo «Prólogo», que no parece tal sino más bien un capítulo cero y a un capítulo I infrecuente, dado su carácter casi enteramente dialogal.

El novelista se declara remiso a cumplir las supuestas tareas descriptivas de todo narrador, consciente además de la fatiga que los lectores habrían de sentir ante la prologada costumbre de dedicar el capítulo inicial íntegro a la presentación del escenario principal. La apostilla que sigue al título del capítulo presupone que las descripciones de escenarios, estáticas por definición, y que por tanto no aportan nada a la trama, ahuyentan al lector: «Rua Ruera, vista de dos lados. (El lector impaciente de acontecimientos recorra con mirada ligera este capítulo, que no es sino el escenario donde se va a desarrollar la acción)».

La advertencia de Ayala anticipa que para «el lector impaciente de acontecimientos» la descripción es una especie de rechazable tiempo muerto en el desarrollo narrativo. El capítulo II es el destinado a presentar lo que en la novela realista era habitual en el I: la descripción panorámica del espacio amplio de la ciudad, el barrio, la calle y la casa destinada a ser el principal escenario de los hechos que, según hemos afirmado, es una modalidad cercana a la convención descriptiva de apertura. Pérez de Ayala convierte este capítulo II en un interesante texto sobre teoría y práctica de la descripción de espacios en novela, combinando una disertación teórica o "poética de la descripción» con la mostración gradual de la ciudad, el barrio, la calle y -culminando el ordenado recorrido, como al desgaire- la casa-zapatería del protagonista.

El narrador hace notar que conoce sus deberes, aunque se le hace difícil el de la descripción. En primer lugar, tras una declaración incoativa, acude en su auxilio el recuerdo de la apertura de La Regenta, que tantos ecos paródicos deja en la narrativa de Pérez de Ayala, singularmente en Belarmino y Apolonio: «Ahora mismo me apercibía yo a describir la Rúa Ruera de la muy ilustre y veterana ciudad de Pilares, en donde vivía Belarmino Pinto [...]».

Enseguida se superpone el recurso con el que Cervantes cedió en 1605 a la convención de escribir un Prólogo, habiendo declarado antes su antipatía por tal obligación. La visita de un amigo que aconseja metaliterariamente al escritor y cuya conversación va al tiempo construyendo el prólogo, también será en Ayala el procedimiento elegido para cumplir la preterida obligación de describir: se le aparece la sombra de don Amaranto, que al ver tan pensativo al narrador, suspendida su tarea de escribir, diserta sobre cómo ha de ser la 
descripción de espacios en novela. La providencial sombra insiste en que no es el narrador el que debe asumir la descripción, sino que cada personaje debe dejar la huella de su punto de vista.

En especial, el perspectivismo se lograría contrastando cómo dos personajes totalmente distintos enfocan la calle que va a ser objeto de descripción. Más adelante, el narrador adopta los consejos, y transcribe un diálogo de dos amigos madrileños -diálogo también de índole teórica- del que él mismo fue testigo en la parte más alta de «la ilustre y veterana ciudad de Pilares», en nueva alusión a la mirada desde lo alto que abre la visión panorámica de Vetusta en La Regenta.

Con sendas ópticas contrapuestas, un filósofo clasicista y un pintor vitalista, viajeros madrileños en la ciudad provinciana de Pilares que encubre a Oviedo, debaten largamente sobre su concepto de ciudad, las estructuras urbanas, el tejido de las calles y sus consecuencias en las relaciones humanas, etc. Sin duda las dos perspectivas desarrollan el problema planteado por Lessing sobre las dos maneras de pintar espacios: la pintura, medio superior, al imitar de manera simultánea, y la palabra, que recrea de manera sucesiva.

La discusión tiene lugar en simultaneidad a la contemplación de la ciudad desde lo alto, una visión que comenzaba siendo panorámica, para luego ir centrándose en las viejas casas de Pilares que, según la alegoría humanizadora de Lirio, el interlocutor artista, «se amontonan, se empujan» y, en otra conexión con La Regenta, «buscan el abrigo de la catedral».

El capítulo se cierra cuando el recorrido visual, y el diálogo que lo acompaña, se acerca a una de las calles, la Rúa Ruera, dentro de la cual y mediante una especie de zoom cinematográfico se acaba por enfocar en primer plano una de las casas. En este punto final, el lector ya tiene delante, perfectamente enmarcado en su contexto, un escenario esencial: la vivienda de uno de los protagonistas, la casa-zapatería de Belarmino.

Otros espacios urbanos serán objeto de someros párrafos descriptivos en adelante. Así, el capítulo III se abre con una breve pero concreta descripción de uno de los lugares de reunión social, el círculo republicano de Pilares, y allí mismo las precisiones toponímicas crean una ilusión de veracidad que, añadida a los detalles urbanísticos del capítulo anterior, dotan a la ciudad de Pilares de un carácter de ciudad real y visitable según las pautas del texto.

Cuatro años más tarde, en 1926, el espacio de Pilares sigue siendo el marco en el que transcurren las novelas complementarias Tigre Juan y El curandero de su honra, y esta recurrencia implica que no es preciso reiterar la presentación de ciertos espacios. El «Adagio» de Tigre Juan que da inicio a la novela se ubica ya directamente en la Plaza del Mercado de Pilares donde tiene su 
puesto Tigre Juan. Mantiene Ayala un interesante modo descriptivo que encadena analogías y usos figurados para presentarnos la plaza y el conjunto de sus casucas como «tertulia de viejas tullidas que se apuntalan en sus muletas y muletillas y hacen el corrillo de la maledicencia», entre decenas de símiles personificadores que anticipan y prejuzgan cómo serán la presencia humana y las relaciones sociales que pueblen ese espacio. La persistente forma figurada de referirse a cada elemento de la plaza (casas, puestos, fuente pública...) convierten en simbólico a este espacio, sin sustraerle por ello su función de decorado realista.

Ya en La Regenta Clarín exploró este procedimiento, tan propio del Naturalismo, de apuntar el paisanaje humano por la vía figurada en un "paisaje sin figuras», sea éste urbano o doméstico. Pero Ayala lo intensifica y concentra en los escasísimos enclaves descriptivos de las citadas novelas, breves pero de suma intensidad. Tras la apertura, sólo encontraremos en adelante esporádicas y muy funcionales referencias a la plaza del mercado, acotaciones mínimas para situar acciones y conversaciones, como el merendero de Buenavista en el exterior de Pilares (en el capítulo «Presto» de El curandero de su honra); algún dato sobre trayectos urbanos, como la llegada a «una plaza que daba a la marina» después de caminar Herminia y Vespasiano por las calles en «Adagio»; la salida de Tigre Juan y su esposa a misa de doce en San Isidoro, sin más precisiones sobre el lugar, pese a ser «la más concurrida de todo Pilares» (en «Coda»).

De igual forma, en el grupo de relatos cortos que componen El ombligo del mundo, conjunto iniciado en 1922, un único espacio cántabro encubierto bajo el nombre de «Valle del Congosto» dota de unidad a los escenarios de la serie de relatos. El conjunto se enmarca con un Prólogo que no responde sólo al convenio del diálogo autorial con el lector característico de todos los prólogos, sino que además inaugura el ámbito de la ficción. Este Prólogo haría las funciones de un capítulo I en las novelas realistas tradicionales, y tal vez por ello Ramón Pérez de Ayala lo encabeza con una advertencia (esta sí, autorial) al lector, presuponiendo de manera cómplice que los capítulos descriptivos o presentativos suelen ser considerados como «prescindibles» por el lector impaciente: «Este prologuillo (de la propia importancia que todos los prólogos) puede el lector impaciente saltarlo de claro sin perjuicio igual que los escalones de entrada a una vivienda a donde se va de visita».

Lejos de ser prescindible, el Prólogo explica la geografía del lugar, la división del valle en dos partes separadas por el río Pallariega, el asentamiento de la villa de Reicastro en la desembocadura del río, su estructura urbana, sus tres iglesias y el castillo ruinoso, etc. Pero, sobre todo, da el tono de las 
novelas, rodea de ironía y juicios de valor lo descrito. Las personificaciones de la naturaleza, las metáforas y analogías para todo lo descrito, los comentarios burlones sobre la inmensa cantidad de topónimos que los habitantes han inventado para nombrar cada accidente de un espacio tan pequeño... inauguran el espíritu crítico de las novelas que han de desarrollar las peripecias de algunos habitantes señalados del valle.

Por último, este prólogo viene a ser también una condensación de cierta estructura -si bien a escala reducida- de novela tradicional: presentación general del hábitat del valle, paisaje, estructura urbana, y clasificación del paisanaje del valle, aunque aún considerado como personaje colectivo o tipificado en grupos, de entre los cuales los relatos que vienen a continuación seleccionarán en adelante sus personajes.

Ayala, pues, parte de convenciones muy asentadas en la novela realista, para experimentar con ellas acercándose y distanciándose de las mismas, movimientos visibles para el lector, y más visibles aún por los frecuentes comentarios metanovelescos que actúan como balizas del realismo novelesco.

Cercanos en el tiempo, los experimentos de otro gran Ramón, Gómez de la Serna, suponen una nueva contrafactura de la presentación de espacios urbanos de la novela del s. XIX.

En la novela de 1923 El novelista, de particular interés por su carácter metanarrativo, podemos señalar eficazmente algunas estrategias. Las «novelas» fragmentarias intercaladas que se atribuyen al protagonista, el novelista Andrés Castilla, constituyen experimentos transparentes, que muestran tanto el proceso como parte del resultado, ya que al lector se le permite compartir el contexto de la invención, la inspiración, las dudas del autor sobre los subgéneros narrativos, sobre los desenlaces, etc., además de los comentarios metanovelescos del narrador marco.

Podemos observar cómo algunos de los experimentos narrativos de Andrés Castilla tenían su origen en un personaje; otros, en una situación insólita; hay incluso la novela de un objeto, el farol. Pero también una ciudad puede ser el punto de partida de un relato. La propia vida urbana de Lisboa impulsa y genera la composición de una novelita titulada «El inencontrable», ya que Andrés Castilla ha ido a Lisboa a escribir la novela que ambientará en esta capital. Claro está que tendrá que hilar una historia, pues sólo de sus impresiones visuales y de descripciones no puede sustentarse su relato. El novelista Andrés Castilla inventa una trama: un detective irlandés recibe el encargo de localizar en Lisboa a un compatriota que vive oculto allí, excelente argumento para mostrar vistas panorámicas desde los miradores de los barrios altos, paseos, recorridos por calles y plazas, entrada en edificios y casas, etc., en 
función de la búsqueda, y también de la propia caracterización del detective como curioso, mirón, flâneur, ingenioso observador de todo lo pequeño... en definitiva, un típico personaje ramonista.

¿A quiénes atribuir las nuevas visiones del entorno? Doctores, enfermos, artistas dilettantes, millonarios extravagantes... (Herrero, 2001: 197-208). ¿Es posible crear una novela desde el designio de describir una ciudad, en este caso la Lisboa que tanto quiso Ramón Gómez de la Serna? Parece ser que sí, y Ramón incluso atribuye a su novelista reflexiones sobre Lisboa como ámbito ideal para hallar materiales novelescos, partiendo de la observación de la propia ciudad, en los comentarios metanarrativos del capítulo XXXIII, significativamente titulado «En la ciudad novelística».

Cuando exista un narrador omnisciente, como el que actúa de marco en El novelista, serán especialmente necesarios los continuos índices de la percepción del personaje, del tipo «x pensaba que», «le parecía que», «veía», «consideraba», seguidos ya de la oportuna imagen o greguería. Una narrativa diferente precisaba, parece claro, nuevos modelos de personaje, caracterizados (si es que puede hablarse de caracterización) por una hipersensibilidad enfermiza, por una creatividad e imaginación desbordantes, que es la que permitirá a Ramón y a otros autores canalizar un nuevo enfoque de la realidad, un insólito punto de vista ante las cosas y el entorno (Román Román, 2008a: 285). Andrés Castilla va creando una novela, de la que conoceremos sólo siete capítulos, un fragmento de otro y el desenlace, transcrito éste en el capítulo XXXVII de la novela marco El novelista. La toponimia urbana real de Lisboa, muy precisa, adquiere gran relieve, pero desde una perspectiva aparentemente aleatoria al depender de los arbitrarios e imprevisibles pasos que da el detective extranjero por la ciudad. Ni el narrador ni el personaje pueden ser ya nuestro guía. No hay designio de orden, al contrario; la ciudad es marco, escenario de una búsqueda al azar, e igualmente los objetos de una tienda, los personajes de una plaza, los transeúntes de una calle, pueden cambiar el derrotero del relato, que pasa a centrarse en ellos hasta que se retoma el hilo conductor de la búsqueda policíaca.

Aunque hay más esbozos de novelas urbanas en El novelista, el que hemos comentado es buen ejemplo de cómo un autor vanguardista crea, y deshace a un tiempo, las expectativas de un lector del género policíaco. El lector de historias e intrigas puede impacientarse con las continuas rupturas de la anécdota que suponen los parones descriptivos, tan indiscriminados que igual corresponden a un alto en la Plaza del Comercio lisboeta, como a la descripción de un bastón en una tienda. Otras expectativas de lectura quedan burladas a lo largo de todo El novelista, libro que como bien señaló Richmond contiene 
elementos «capaces de excitar y al mismo tiempo frustrar la fantasía del lector» (Richmond, 1989: 209).

La importancia de las calles y del deambular por ellas como situación muy frecuente en varias de las novelitas que esboza el protagonista Andrés Castilla, es un aspecto notado por Valis. Un breve texto, incluso, el que constituye el capítulo V del conjunto, se titula «La novela de la calle del Árbol», y transcribe un inicio de novela en primera persona para la que Andrés Castilla se inspira en su calle, fantaseando con las muchas vidas-novelas que contiene cada casa, cada balcón. Es comprensible el desconcierto que puede producir en el lector «de historias» la burla que Ramón hace de todo tipo de narraciones en las que prevalece la aventura, el contar. (Valis, 1986: 419).

Ni la reflexión metaliteraria sobre técnicas descriptivas, ni el triunfo de la descripción sobre la narración que hemos subrayado en los dos Ramones, serán del gusto de un cierto tipo de lectores de novela. Pero hay lectores para todo, y para todos. Sin duda este tipo de relatos apelan a un lector más sofisticado que el de las novelas del siglo XIX que asentaron las convenciones urbanas. El lector que en el siglo XXI se enfrente a novelas del siglo XIX y del siglo XX, puede disfrutar no sólo de la lectura individual de cada obra, sino de la confrontación de los modelos y sus contrafacturas, es decir, de la construcción de la propia historia literaria.

\section{BIBLIOGRAFÍA}

Alarcos Llorach, Emilio, «Notas a La Regenta», Archivum, Oviedo, II, 1952, pp. 141-160.

AlBIAC, María Dolores, «Perseo y el espejo. Autobiografía y literatura en la preguerra europea», en La novela en España. Siglos XIX y XX, ed. de Paul Aubert, Madrid, Collection de la Casa de Velázquez, vol. 66, 2001, pp. 111-123.

AMORós, Andrés, Prólogo de la edición de R. Pérez de Ayala, La pata de la raposa, Barcelona, Labor, 1970, pp. 26-28.

ANDERSON, Farris, «Madrid y el espacio de Miau», Cuadernos Hispanoamericanos, $n^{\circ}$ 521, noviembre 1993, pp. 23-36.

AyalA, María Ángeles y Enrique Rubio, «Introducción» de Antología costumbrista, Barcelona, El Albir, 1985, pp. 9-78.

BAKER, Edward, Materiales para escribir Madrid. Literatura y espacio urbano de Moratín a Galdós, Madrid, Siglo XXI Editores, 1991.

BALZAC, Honoré de, La comedia humana, I, traducción de Rafael Cansinos Assens, Madrid, Aguilar, 1987.

BARTHES, Roland, El placer del texto, traducción de Nicolás Rosa, Madrid, Siglo XXI Editores, 1974. 
Bobes NAVES, María del Carmen, Teoría General de la novela. Semiología de La Regenta, Madrid, Gredos, 1985.

BReton, André, Manifiestos del Surrealismo, traducción de Andrés Bosch, Barcelona, Labor, 1992.

Coronado, Carolina, La Sigea, en Obra en prosa, Novelas I, edición, introducción y notas G. Torres Nebrera, Badajoz, Editora Regional de Extremadura, 1999a.

Coronado, Carolina, Luz, en Obra en prosa, Novelas II, edición, introducción y notas G. Torres Nebrera, Badajoz, Editora Regional de Extremadura, 1999b.

ESCOBAR, José, «Narración, descripción y mímesis en el «Cuadro de costumbres»: Gertrudis Gómez de Avellaneda y Ramón Mesonero Romanos», Romanticismo, 3-4, Genova, Università di Genova, 1988, pp. 53-60.

Escosura, Patricio de la, Estudios históricos sobre las costumbres españolas, Madrid, Imprenta de la Sociedad Tipográfico-Editorial, 1851.

Ganivet, Ángel, Los infatigables trabajos de Pío Cid, ed. de Laura Rivkin, Madrid, Cátedra, 1983.

GRIVEL, Charles, Production de l'intérêt romanesque, The Hague/Paris, Mouton Ed., 1973.

Herrero Vecino, Carmen, «El concepto de enfermedad en las novelas de Ramón Gómez de la Serna (1914-1934)», Siglo Diecinueve, 7, 2001, pp. 197-208.

HuRTADO, Antonio, Corte y cortijo, edición, estudio preliminar y notas de Isabel Román Román, Editora Regional de Extremadura, col. Rescate, 2010.

KRONIK, John H., «La resonancia del realismo: Galdós y Clarín entre fines de siglo», RILCE, 15, 1, 1999, pp. 93-104.

LÓPEZ-LANDy, Ricardo, El espacio novelesco en la obra de Galdós, Madrid, Eds. Cultura Hispánica, 1979.

LOZANO SAMPEDRO, María Teresa, «El espacio y la mirada o el hombre como espejo del universo en Balzac y Baudelaire: «Limmensité intime», en Espacio y texto en la cultura francesa, Tomo II, El espacio en la teoría literaria y la literatura francesa, Angeles Sirvent Ramos ed., Universidad de Alicante, 2005, pp. 1005-1021.

Mesonero Romanos, Ramón de, Escenas y tipos matritenses, ed. de E. Rubio Cremades, Madrid, Cátedra, 1993.

Molino, Jean,»Logiques de la description», Poétique, nº 91, 1992, pp. 363-383.

PÉREZ DE AyAla, Ramón, La pata de la raposa, ed. de Andrés Amorós, Barcelona, Labor, 1970.

PÉREz GALdós, Benito, El doctor Centeno, edición, estudio preliminar y notas de Isabel Román Román, Cáceres, Servicio de Publicaciones de la Universidad de Extremadura, 2008.

Richmond, Carolyn, «Ramón Gómez de la Serna, novelador de El novelista», AIH, Actas, 1989, pp. 209-214. 
ROMÁN ROMÁN Isabel, «Greguería y novela en Ramón Gómez de la Serna y Eugenio D'Ors», en AA. VV. Del Siglo de Oro y de la Edad de Plata. Estudios sobre literatura española dedicados a Juan Manuel Rozas, Servicio de Publicaciones de la Universidad de Extremadura, 2008a, pp. 283-294.

RomÁn Román Isabel, «Estudio Preliminar», Benito Pérez Galdós, El doctor Centeno, Cáceres, Servicio de Publicaciones de la Universidad de Extremadura, colección TextosUex, 2008b, pp. 12-100.

ROMÁN ROMÁN Isabel, «Las interferencias en la lectura de la narrativa de Galdós, según sus contemporáneos», en Le roman espagnol entre 1880 et 1920: état des lieux, Coordination Élisabeth Delrue, Université de Picardie, Indigo, 2010, pp. 87-106.

RomÁn Román Isabel, «Carolina Coronado y el envés irónico de la novela popular», Badajoz, Alborayque, nº 5, 2011, pp. 109-132.

Russell, R. A. «Percepción, proporción y onomástica en La de Bringas», Actas del IV Congreso Internacional de Estudios Galdosianos, Las Palmas, Cabildo de Gran Canaria, 1993, pp. 817-822.

SÁdAba Alonso, Soraya, «Espacio y personajes en Misericordia de Benito Pérez Galdós», Cuadernos de Investigación Filológica, 27-28, 2001-2002, pp. 63-80.

SEBOLD P., Russell, La novela romántica en España. Entre libro de caballerías y novela moderna, Salamanca, Eds, de la Universidad de Salamanca, 2002.

SETA, Cesare de, Ritratti di città. Dal Rinascimento al secolo XVIII, Torino, Giulio Einaudi, 2011.

VALIS, Nöel M., «El novelista Ramón Gómez de la Serna», AIH, Actas, IX, 1986, pp. 419-427.

ZoLA, Émile, «Sobre la descripción», El Naturalismo, traducción de Jaume Fuster, selección, introducción y notas de Laureano Bonet, Península, col. NeXos, Barcelona, 1989, pp. 199-204.

Zubiaurre, María Teresa, El espacio en la novela realista, México, Fondo de Cultura Económica, 2000.

Fecha de recepción: 31-10-2011

Fecha de aceptación: 30-03-2012 